\title{
Culture brokering: The essence of
}

nursing care for preschool children suffering from cancer-related pain

by Suzan Banoub-Baddour and Maureen Laryea

\section{Abstract}

Caring for preschool children suffering from cancer pain presents a major challenge for paediatric oncology nurses. These children have limited language and behavioural competencies. They are also constantly experiencing cancer pain originating from various sources. Their needs hence have to be interpreted by their parents. Besides other complex factors, the parental beliefs strongly influence the child's pain perception, expression and response. In most paediatric oncological nursing settings, every encounter between the nurse, the child's parents and the child constitutes a cultural encounter. In a dyadic relationship with the parents, the nurse needs to act as a culture broker bridging the cultural gap between the parents, the child and self, as well as between the parents, child and other health professionals.

In this article, the pain assessment and management of a preschool child with cancer, using the concept of culture brokering as a nursing strategy, is discussed.

Pain recognition, assessment and management in the paediatric oncological population remains a complex problem, particularly in the preschool child (three to five years) who may not be very articulate. The paediatric nurse is in a unique position to help change this unfortunate situation especially as a child and family advocate (Whaley and Wong, 1991). Such advocacy is basic to the

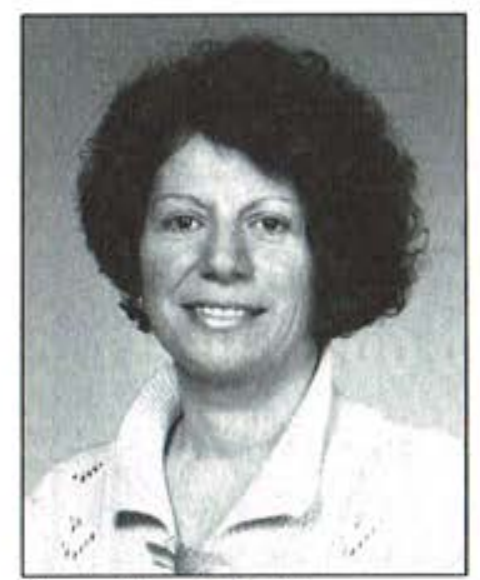

Suzan Banoub-Baddour

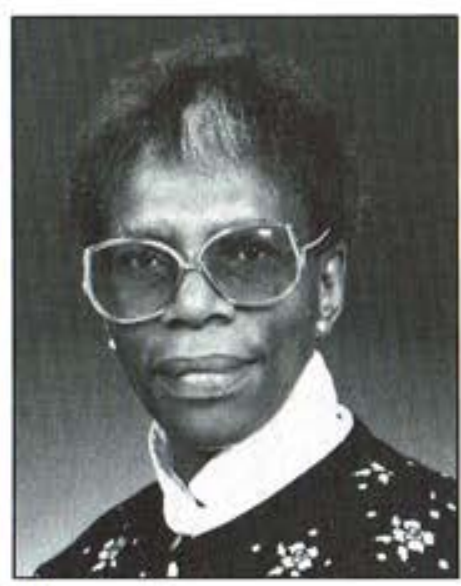

Maureen Laryea concept of culture brokerage (Tripp-Reimer and Brink, 1985).

The purpose of this paper is to examine the concept of nurses as culture brokers in the care of preschool children suffering from cancer pain. The management of cancer pain in young patients with limited verbal capabilities has been specifically chosen to help illustrate the application of a concept relatively new to nursing, that of culture brokering.

Throughout this article the terms "parent" and "family" are used interchangeably. Depending on the situation, the terms "parent" could be substituted by "guardian". The term "client" refers to the paediatric patient of preschool age and his/her family. The term "culture" is used as defined by Leininger (1985, p.205) as "the values, beliefs, norms and practices of a particular group that are learned and that guide thinking, decisions and actions in a patterned way."

This paper is organized in the following sequence: First, the pain experience of preschool children diagnosed with cancer is described, taking into account the role parents play in its management; second, a discussion of the concept of culture brokering as one nursing strategy in the care of preschool children suffering from cancer pain is presented; lastly, suggestions for culture brokering interventions in the pain assessment and management of these children are examined.

\section{The pain experience of preschool children diagnosed with cancer}

Even when the type of cancer has a favourable prognosis, the life of a preschool child is drastically interrupted by the cancer and its pain. The preschool child with cancer experiences pain from various etiologies: Cancer-related pain which is pain directly caused by the

\section{LE COURTAGE CULTUREL: UNE STRATÉGIE INFIRMIËRE POUR LA GESTION DE LA DOULEUR DU CANCER CHEZ LES ENFANTS D'ÂGE PRÉSCOLAIRE}

\section{ABRÉGÉ}

Les soins dispensés aux enfants d'âge préscolaire souffrant de douleurs du cancer représentent un défi de taille pour les infirmières en oncologie pédiatrique. Ces enfants ont des compétences linguistiques et comportementales limitées. De plus, ils souffrent constamment de douleurs cancéreuses ayant plusieurs origines. Il faut donc que les parents interprètent leurs besoins. En plus d'autres facteurs complexes, le système des valeurs des parents influe grandement sur la façon dont l'enfant perçoit et exprime la douleur et y réagit. Dans la plupart des domaines des soins infirmiers d'oncologie pédiatrique, toute rencontre entre l'infirmière, les parents de l'enfant et l'enfant lui-même constitue une rencontre culturelle. Dans un tel rapport dyadique avec les parents, l'infirmière doit jouer le role du courtier culturel qui comblera les lacunes culturelles existant entre les parents, l'enfant et elle-même, ainsi qu'entre les parents, l'enfant et les autres professionnels de la santé.

Cet article présente l'évaluation et la gestion de la douleur chez un enfant d'âge préscolaire, en soulignant l'emploi du concept du courtage culturel en tant que stratégie infirmière.

Suzan Banoub-Baddour RN DNSc and Maureen Laryea RN, M. Phil. are associate professors in the School of Nursing at Memorial University of Newfoundland, where they teach in the graduate and undergraduate programs. They are interested in cultural issues and their impact on nursing care. 
malignancy; treatment-related pain which is pain caused by drugs, side-effects of chemotherapy, radiation or pain subsequent to surgery; procedural pain which is associated with bone marrow aspirations or biopsies, lumbar punctures, blood test injections, and occasionally pain associated with trauma, debility (eg. bed sores), or from pre-existing medical conditions (Miser and Miser, 1989).

McGrath (1989) described a child's pain as an unpleasant sensory and emotional experience which varies between children and even within the same child at different times depending on a multitude of factors. Some factors are relatively constant for a given child, and others vary dramatically depending on each new situation. These factors are illustrated in Table One, and for the purpose of this article, only three will be discussed in this section, namely, the child's cognitive development, culture and family learning, as these are seen to be amenable to culture brokering interventions.

Preschool children fall in the pre-operational stage of cognitive development (Piaget, 1952). In a research study done by Hurley and Whalen (1988) on children's perception of pain, preschoolers were found to function "on a prototaxic mode of thinking, meaning that they relate in the moment and respond best to interaction that is here and now" (p. 23). Preschoolers who participated in this research also described pain primarily as a physical experience and, because of their egocentricity, tended either to hold someone responsible for their pain, or perceive it as a punishment for something they did. Such thinking about the nature of their pain, compounded by their limited language development, made it difficult for the preschool children who participated to identify and clearly describe their pain, their distress and their related needs. The researchers observed a tendency of these children was therefore to "strike out physically and verbally when they hurt" (Hurley and Whalen, 1988, p.23). Related behaviours indicating sadness and withdrawal were also noted.

The preschool child's limited experience with pain, as well as the learning acquired through observing the pain experiences of others can influence how the child with cancer pain will react (Ross and Ross, 1988; McGrath, 1989). The impact of the child's personal life experience can be observed in cases of children whose pain has been present for a relatively long period of time or has even increased gradually. It is believed that in such cases the pain sensation may become incorporated into the preschool child's body image. Some authors suggest that in such instances pain and suffering may be perceived as "normal" and these children may not communicate it (Meinhart and McCaffery, 1983).

Parents or guardians are the major socializing agents for the preschool child and therefore have a great influence on the child's cancer pain experience (Boyle and Andrews, 1989). Through their own upbringing or the way they were parented, their education and cultural heritage, they help to shape the child's pain experience. Ross and Ross (1988) argue that the meaning parents assign to cancer pain, their own pain behaviour, their perceptions of the child's pain and their reactions to its expression, all are transmitted to the child. This occurs mainly through the parent-child relationship and the practised discipline in the home. Moreover, direct "training" is often offered early in life by the parents. For example, in what could be seen as culture-specific training, the parent may instruct the child "about how much discomfort justifies a complaint, the acceptable ways of expressing such complaints, who to approach about them, what is likely to happen as a result, and when to terminate the complaint" (Ross and Ross, 1988, p. 80; Abu-Saad, 1984). A preschool child also utilizes the pain vocabulary commonly used at home (using words such as "ouch", "owie", "booboo", or "hurt"). Thus as the child grows he/she learns specific familial as well as cultural norms related to pain.

\section{Culture brokering: A nursing strategy}

Culture brokering or brokerage basically involves translation of messages, instructions and belief systems, and processing them from one group to the other. It may be used whenever distinct cultural groups are encountered within a variety of social situations. It is hence viewed as an act of bridging, negotiating or linking those diverse groups (Tripp-Reimer and Brink, 1985; Jezewski, 1990). The concept has its origin in anthropology and has been introduced into nursing practice by pioneers in transcultural nursing such as Toni Tripp-Reimer and Pamela Brink. As a nursing intervention, culture brokering involves nurses acting as mediators between the lay client and the scientific health professional. More than an intervention for other health professionals, culture brokering is a nursing intervention because the nurse's educational preparation emphasizes the social and biological sciences, and because nurses usually have the closest relationships with clients and their families (Tripp-Reimer and Brink, 1985).

Recent literature supports the concept's relevance to the nursing care of adult oncology patients (Sharman, 1988), and migrant farm workers (Jezewski, 1990). The concept of culture brokering is even more appropriate to the specialty of paediatric oncology nursing, in general, where families are closely involved in the care of their children, and specifically, to the management of preschool children's cancer pain, whether an acute or chronic pain from various etiologies.

In paediatric oncology settings, the preschool children draw upon their families' health beliefs, values and practices. In the course of giving care, the nurse brings her professional health beliefs, values and practices. Each encounter between the child, family and the nurse constitutes, then, a cultural encounter where incongruencies of views about the causation, meaning and treatment of cancer pain in the child are likely to occur. Therefore, the nurse can act as a culture broker to bridge the gap between the child, the parents and the nursing profession. As mediator, the nurse could also assist other health practitioners who need to adapt their approach, their communication or their intervention strategies so that they are more appropriate for the child and family. Hence, culture brokering may be directed towards the client, the health professional, or toward mediating between both.

Culture brokering has then a broader scope than most nursing interventions which focus primarily on altering specific aspects of the client's health. It thus differs from just considering cultural issues while using the nursing process. According to Tripp-Reimer and Brink (1985), the nursing textbooks that deal with transcultural issues have assigned an important section to the content necessary in a cultural assessment. The emphasis has been on what Leininger (1978) calls a "culturalogical assessment", focusing on the content rather than the process. In contrast, the former two authors

\section{Table One: Multitude of factors affecting a preschool child's cancer pain experience}

\begin{tabular}{l|l|}
$\begin{array}{l}\text { Physiological: } \\
\text { - Neuro physiological } \\
\text { - Sensory }\end{array}$ & $\begin{array}{l}\text { Emotional: } \\
\text { - Fear, anger, frustration }\end{array}$ \\
\hline $\begin{array}{l}\text { Behavioural: } \\
\text { - Coping style } \\
\text { - Parental response }\end{array}$ & $\begin{array}{l}\text { Experiential: } \\
\text { Understanding of pain source } \\
\text { Expectation regarding quality } \\
\text { and intensity of pain } \\
\text { - Meaning of pain } \\
\text { - Previous pain experience }\end{array}$ \\
$\begin{array}{l}\text { Constant Factors: } \\
\text { - Gender }\end{array}$ & $\begin{array}{l}\text { - Fagnitive level } \\
\text { - Culture } \\
\text { - Child-parent relationship }\end{array}$ \\
\hline $\begin{array}{l}\text { (Adapted from Stevens, Hunsberger and Browne (1987) and } \\
\text { McGrath (1989). }\end{array}$
\end{tabular}


recommend as one culture brokering technique to "treat cultural assessment as a process rather than simply a content area" (Tripp-Reimer and Brink, 1985, p.358). Such an approach will help identify the client's health and illness beliefs and values so that they can be understood and incorporated into his/her health care, hence assisting rather than interfering with the possible treatment outcome (Harwood, 1981; Kleinman, Eisenberg and Good, 1978.)

Illness and treatment regimens must make sense to the client and to the parents in terms of their psychological and social worlds; similarly, some of the patient's private world must be explained to the health professionals (Schwab, Drake and Burghardt, 1988). This would involve, for instance, translating what the child and his or her family mean, or their subjective experience of the cancer and its pain into a terminology and a frame of reference readily understood by the health professional (Tripp-Reimer and Brink, 1985).

Other intervention techniques for culture brokering include: 1. Patient advocacy which is a well-established nursing intervention strategy;

2. Negotiation: This is used when a conceptual difference (eg. using the same words but actually meaning different things, or applying a term to the same phenomenon but having different notions of its causation) exists between the client and the health professional, and 3. The therapeutic use of time, ie. setting aside sufficient time for the child and family to absorb specific information (eg. about treatment alternatives), while encouraging the presence of significant others during all phases of the health encounter. Probably except in life-threatening situations, and regardless of the age group involved, instant decisions in the care of the oncology patients deprive them of the right to work through decision-making at their own pace (Tripp-Reimer and Brink, 1985).

If properly used in the management of cancer pain, culture brokering can result in increased child and family satisfaction and adherence to the prescribed treatment regimen, as well as increased health professional satisfaction and decreased frustration (Tripp-Reimer and Brink, 1985).

\section{Culture brokering interventions: Cancer pain recognition, assessment and management}

Caring for preschool children suffering from cancer pain presents a major challenge for paediatric oncology nurses. Because of the complex nature of a preschool child's cancer pain, the use of a multidisciplinary pain management team involving health care professionals with diverse expertise has been recommended. The nurse or paediatric oncologist may lead this team, ideally composed of the radiation therapist, surgeon, anesthesiologist, physical and play therapist, dietitian, pharmacist, teacher, social and pastoral worker and the psychiatrist (Miser and Miser, 1989). Including the child and parent as essential members of their pain management team is primordial. The younger the child (eg. three to four years, as opposed to five years or older), the more continuous and intense is the need for the family's involvement.

\section{Pain assessment approaches}

Because management of cancer pain in the preschool child is not straightforward, the nurse needs an adequate knowledge of the available pain assessment and pain-relieving strategies, and a sound understanding of the management of cancer. Relying on any single assessment method or indicator of pain has been reported to be "dangerously limiting", and a multidimensional approach is essentially required (McCaffery and Beebe, 1989, p.276). Three important components to such an approach are:

1. Discussions about pain that include the child, parents, other caregivers and health professionals;

2. Self-reports obtained by playing or talking with the child using the child's pain vocabulary, and

3. Observations of the child's vocalizations, facial expressions, body movements, physiological responses, and changes in daily activities and usual behaviours. Validation, of what the nurse and the parents perceive the child's pain behaviours to be, with one another is crucial. This will avoid many inaccurate judgments that could be triggered by failing to establish what specific words mean to the child, or by misinterpreting a child's denial of the pain for fear of receiving an injection (McCaffery and Beebe, 1989). Moreover, parents are also needed to explain any unusual or unexpected child's behaviour that may be indicative of pain.

Currently, there are several simple, valid and reliable tools for pain assessment in children three years and older. However, their reliability and validity in a culturally diverse population may need to be further explored. The "Pain Experience History" (Whaley and Wong, 1991) and other pain interview approaches can be utilized with both the child and parent as informants. Preschoolers who lack verbal fluency, or who do not understand the language spoken by the nurse, can be assessed using non-verbal tools such as: the Beyer's "Oucher" Tool (Beyer, 1988) and the Eland Color Tool (Eland, 1985).

In addition to the normative pain assessment data, more specific, subjective cultural data are needed. Such cultural data directs the nurse to assess health beliefs, practices and values of the parents that may hinder or promote the nursing intervention or medical treatment of their child's pain (Boyle and Andrews, 1989; Tripp-Reimer, Brink and Saunders, 1984). For instance, it is important that the nurse ascertains from the parents the measures they would normally use to ease the child's distress.

The authors of this article propose the use of the forms that could be used for recording the pain data by both the nurse and the parents. This would facilitate the nurse's role as culture broker by ensuring the consistent involvement of the parent in the child's pain assessment and evaluation (Figures One and Two). Moreover, such forms would help ensure that the gathered information is adequately processed and communicated to other members of the multidisciplinary pain management team.

\section{Pain management approaches}

In order to plan for an adequate pain relief strategy, the nurse needs to identify as closely as possible, with the rest of the health care team, the etiology of pain (eg. tumour-related or treatment related). As a mediator, the nurse will then explain to the parent the identified etiology, the meaning of that pain in relation to the course of the disease, and the planned pain relief strategies. The child's prior analgesic history needs also to be carefully screened, as well as his/her ability to take oral medications. Besides identifying any drug allergy or toxicity experienced by the child, such history will also help identify parental beliefs or "family biases" against specific drugs eg biases related to drugs causing addiction, or to be "saved for something worse" (Miser and Miser, 1989, p.985).

Pain management modalities range from pharmacological to non-pharmacological strategies. Three important key concepts should guide the use of analgesics in cancer pain in preschool children. These include using a preventative approach; titrating or individualizing the dose of analgesic, and ensuring self (if appropriate) and parental control of the child's pain relief. Because analgesic orders are usually given as needed, the nurse needs to know that it can be implemented around the clock (McCaffery and Beebe, 1989), especially if a flow sheet (eg. Figure Two) is used. [Miser and Miser (1989) and Foley and Whittam (1990) provide an overview of the pharmacological management of the child with cancer pain to which readers are referred.]

Two major groups of non-pharmacological interventions are proposed here and should be used in conjunction with analgesics. They include culturally appropriate cognitive and affective interventions. The first group involves strategies to provide "factual information designed to alter the child's perception". They offer a "warning of what would happen and how it would feel" (Broome and Lillis), 1989, p.76). Some examples are: Puppet therapy, sensory and procedural preparation tailored to the child's capabilities; cartoons or coloured books with pictures; story-telling which is culturally relevant and narrated by parents 
or grandparents. Any harmless folk remedy or practices which the parents suggest could also be included because of its psychological value.

The second group which includes affective interventions is designed to provide the preschooler "with coping skills and emotional support during the painful experience." (Broome and Lillis, 1989. p.77). Both the parent and the nurse work to select strategies that would help the child cope with the pain. These include any or a combination of the following: The parent's presence, holding the child's hands, and the use of distraction techniques such as procedural play (Suderman, 1990); breathing exercises; guided imagery using an imaginary friend or a cartoon hero; music;

\section{Figure One: Initial preschool child cancer pain assessment*}

\section{Child's Name:}

Age:

Date:

Parent's Initials:

Nurse's Initials:

1. Location of pain: (a drawing of child's body

2. Manner of expressing pain:

could be marked by child, parent, or nurse)

3. Onset, duration, variations, rhythms:

4. What causes or increases the pain?

5 . What relieves the pain?

6. Intensity: (as described by child and parent)

7. Quality: (if possible, use child's words).

8. Effects of pain: (Note decreased function) eg:

Appetite:

Sleep:

Physical Activity:

Play:

Relationship with others (eg. irritability):

Emotions (eg. anger, crying):

Smile:

Accompanying symptoms (eg. nausea, vomiting):

9. Other behaviour(s) or comments (eg. child wanting to be held):

10. Associated anxiety-provoking signs/symptoms or situation(s):

-To be completed by both nurse and parent(s)

(Adapted from Harwood [1981] and McCaffery, M.

\& Beebe, A. (1989]). drawings; story-telling; humour (eg. clowning), and the use of a distraction box (Salton, 1990) adapted to the child's age. Encouraging the child to be involved with visitors such as siblings, grandparents, friends, or neighbours may also be helpful. Depending on the child's and family's spiritual beliefs and practices, prayers could be also encouraged (Abu-Saad, 1984).

Another important culture brokering intervention in the pain management is for the nurse to evaluate continuously all the dynamic "situational, familial, emotional and behavioural factors" that may modify the child's pain response. Such evaluation will allow the understanding of the very framework in which the child perceives pain (McGrath, 1989, p.211), and can create the supportive environment that is most likely to result in optimal pain relief. As Harwood (1981) described it, for most lay persons relief from pain generally indicates the patient is improving (or at least not deteriorating); every effort hence must be spent in the process of creating and maintaining that supportive environment. Therefore, other related symptoms or conditions must be taken into account in the management of cancer pain in the preschool child, such as:

1. Relief from the signs and symptoms that are most anxiety-provoking for the child or family - such as constipation or drowsiness frequently associated with the use of analgesics - and 2. The promotion of ways of coping with the limitations on valued activities due to the medical or nursing regimen. These nursing actions are integral to the development of the child and family's hopeful and positive attitudes toward cancer and its pain, as well as to the promotion of adherence (Harwood, 1981) to the prescribed regimen. Such an approach is one goal of culture brokering.

In summary, in order to be an efficient culture broker whether in the assessment, management or evaluation phases dealing with a preschool child's cancer pain, the nurse needs cultural awareness and sensitivity, respect, creativity, sound knowledge of paediatric pain and its management, and good communication, negotiation and advocacy skills.

\section{Conclusions}

Preschool children with cancer pain present a major challenge for paediatric oncology nurses. At this young age, the child's pain experience is influenced by his/her unique physiological, psychological and developmental status, the disease process and its therapy, and the family's cultural background. Moreover, the child's pain management is also influenced by the nurse's and other health professionals' beliefs and practices. Every encounter between the nurse or health professionals, the child and the parents constitutes a cultural encounter in which the nurse can adopt a culturally-sensitive perspective. The use of culture

\section{Figure Two: Ongoing Preschool Child Cancer Pain Relief Evaluation*}

Child's name:

Parent's initials:
Age:

Date:

Nurse's initials:

\begin{tabular}{||c|c|c|c|c|c||}
\hline \hline Time & $\begin{array}{c}\text { Pain } \\
\text { Description }\end{array}$ & Analgesic & $\begin{array}{c}\text { Other Methods of } \\
\text { Pain Relief }\end{array}$ & $\begin{array}{c}\text { Child's } \\
\text { Response }\end{array}$ & $\begin{array}{c}\text { Parents } \\
\text { Comments }\end{array}$ \\
\hline & & & & & \\
\hline
\end{tabular}

*To be completed by both nurse and parent(s).

(Adapted from McCaffery, M. Beebe, A. (1989) Pain: Clinical Manual for Nursing.) 
brokering in the pain recognition, assessment and management is one of the nursing intervention strategies that will helpoptimize the management of the child's cancer pain. In this strategy, the nurse acts as a mediator between the child, parent and health professionals, bridging the cultural gap. As a member of the multidisciplinary pain management team, the nurse involves the child and parents in the use of pharmacological, and culturally appropriate cognitive and affective interventions.

Note: The authors wish to thank Debra Ward, research assistant, for helping edit the manuscript.

\section{References}

1. Abu-Saad, H. (1984). Cultural Components of Pain: The Arab-American Child. Issues in Comprehensive Pediatric Nursing, 7,91-99.

2. Adams, J. (1989). Pediatric Pain Assessment: Trends and Research Directions. Journal of Pediatric Oncology Nursing, 6, 3, 79-85.

3. Beyer, J. (1988). The Oucher: A user's manual and technical report. Denver, $\mathrm{Co}$; University of Colorado.

4. Boyle, J.S. and Andrews, M.M. (1989). Transcultural Concepts in Nursing Care. Boston: Scott Foresman Co.

5. Broome, M.E. and Lillis, P.P. (1989). A descriptive analysis of the pediatric pain management research, Applied Nursing Research, 2, 2, 74-81.

6. Fand, J. (1985). The child who is hurting Seminars in Oncology Nursing 1, 116-122

7. Folcy, G.V. and Whittam, E.H. (1990). Care of the Child Dying of Canoer: Part I. CAA Cancer Journal of Clinicians, 40, 6, 327-355.

8. Harwood, A. (1981). Introduction in Ethnicity and Medical Care. Cambridge M.A.: Harvard University Press.

9. Hurley, A. and Whalen, E.G. (1988). Cognitive Development and Children's Pediatric Nursing, 14, 1, 21-23.

10. Jezewski, M.A. (1990). Culture brokering in migrant farm workers. Health carc. Western Journal of Nursing Research, 12, (4), 497-573.

11. Klcinman, A., Eisenberg, L, and Good, B. (1978). Culture, illness and care: Clinical lessons from anthropological and cross-culture research. Annals of Internal Medicine, 88, 251-258.

12. Leininger. M. (1978). Culturalogical Assessment Domains for Nursing Practices, in Leininger M (ed). Transcultural Nursing, Concepts, Theories, and Practice New York: John Wilcy and Son.

13. 1 cininger. M. (1985). Transcultural care diversity and universality: A theory of nursing. Nursing and Health Care, 6, 4, 204-212.

14. McCaffery, M. and Beebe, A. (1989). Pain: Clinical Manual For Nursing, St. Louis: C.V. Mosby Company.

15. McGrath, P.A.(1989). Evaluating a child's pain. Journal of Pain and Symptom Management, 4, 4, 197-217.

16. Meinhart, N.T. and McCaffery, M. (1983). Pain: A Nursing Approach to Assessment and Analysis. Norwalk, Connecticut: Appleton Century-Crofts.

17. Miser, A.W. and Miser, J.S. (1989). The treatment of cancer in children. Pediatric Clinics of North America. 36, 4, 979-9999.

18. Piaget, J. (1952) (translated by Margaret Cook). The origins of intelligence in children. New York: International University Press.

19. Ross, D. and Ross, S. (1988). Childhood Pain. Battimore: Urtan and Sctwarzenberg, 20. Salton, C. (1990). The distraction box: A strategy to help patients cope with pain. Poster presentedat the Third National CANOConferenoe, Saskatoon, Sept. 1990. 21. Schwab, B., Drake, R.E., and Burghardt, E.M. (1988). Health Care of The Chronically Mentally III: The Culture Broker Model.

22. Sharman, S.B.(1988). Bridging the gap. Anthropological Brokering Nursing Care. Unpublished PhD. Thesis submitted to the University of South Forida. 23. Stevens, B., Hunsberger, M. and Browne, E. (1987). Pain in Children, Research and Practice Dilemmas. Journal of Pediatric Nursing 2, 3, 154-166.

24. Suderman, J.S. (1990). Pain relief during routine procedures for children with leukemia. MCN, 15, 163-166.

25. Tripp-Reimer, T.R.,Brink, P.J.(1985). Culture Brokerage. In Bulechek, G.M., McCloskcy, J.C. (Eds). Nursing Interventions: Treatments for Nursing Diagnoses. Boston: W.B. Saunders Company, 352-364.

26. Tripp-Reimer, T. Brink, P.J. and Saunders J.M. (1984). Cultural Assessment Content and Process. Nursing Outlook, 32, 2, 78-82.

27. Whalcy, L., Wong, D. (1991). Nursing care of infants and children. (Fourth edition) Boston: Mosby Yearbook. p.17.

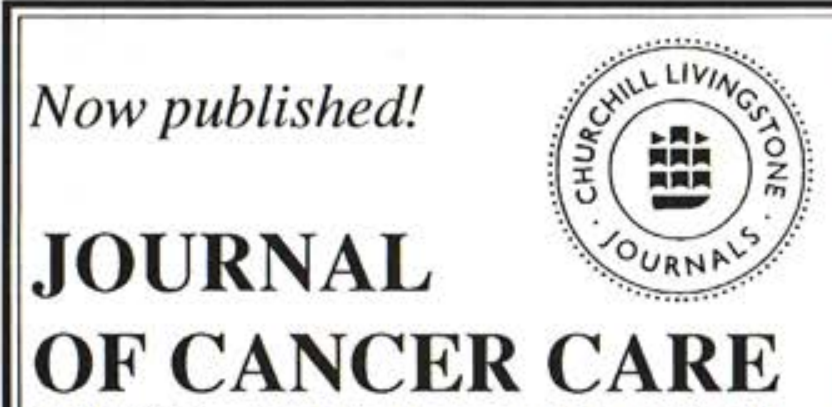

EDITORS: Ann Faulkner and Irene Scott

\section{THE JOURNAL OF CANCER CARE}

covers cancer care in hospitals, homes and hospices.

Prevention...early detection....acute, treatment-oriented

care...continuing care...palliative care.

PLUS...rehabilitation...psychological care, care of family members, support mechanisms for formal and informal carers...psychological impact of illness and attitudes to cancer...oncology education in Europe and the rest of the world.

\section{CONTENTS OF FIRST ISSUE INCLUDE:}

Childhood cancer: psychosocial needs Are they being

met?/G Peace, C O'Keefe, A Faulkner, J Clark

Shared care in paediatric oncology/K R Muir.

$S E$ Parkes, R Boon, M C G Stevens, J R Mann

Cancer Centre profile: The Christie Hospital/I Scott

Quality of life/B M Traynor

Advances in symptom control for dysphagia and

dyspnoca/N P Sykes

Health promotion:testicular self examination/M Johnson

\section{SUBSCRIPTION INFORMATION}

ISSN 0960-9768 4 issues Vol 11992

Member rate $\quad 120$ (UK) $\$ 22.50$ (EwiO's) $\$ 42.50$

(RCN, Cancer Relief Macmillan Fund and other nursing organisations)

Individual rate 149 (UK) $\$ 51.50$ (EuriO's) $\$ 90$ (USA)

Institutional rate 179 (UK) 283 (Eur/O's) \$I4S (USA)

\section{FREE SAMPLE COPY OFFER!}

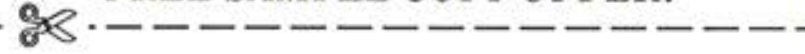

\section{JOURNAL OF CANCER CARE}

Yes! Please send me a sample copy.

Name

Address

Postcode

Return to: Churchill Livingstone Journals

Robert Stevenson House

1-3 Baxter's Place, Leith Walk

92/OC/CANO

EDINBURGH, EHI 3AF, Scotland, UK 